\title{
Effect of Heat load on a Mechanical Forging Press
}

\author{
Zdenek Chval \& Karel Raz
}
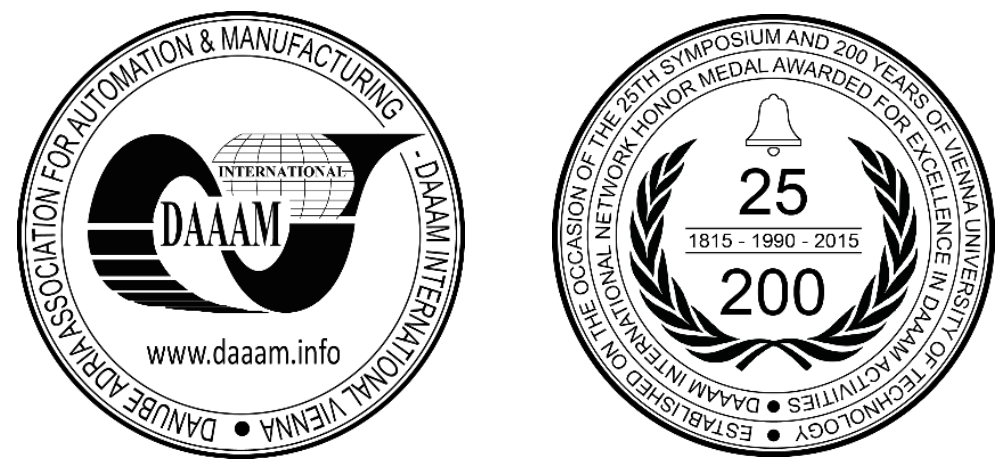

This Publication has to be referred as: Chval, Z[denek] \& Raz, K[arel] (2016). Effect of Heat Load on a Mechanical Forging Press, Proceedings of the 27th DAAAM International Symposium, pp.0344-0348, B. Katalinic (Ed.), Published by DAAAM International, ISBN 978-3-902734-08-2, ISSN 1726-9679, Vienna, Austria

DOI: $10.2507 / 27$ th.daaam.proceedings.050

\begin{abstract}
This article deals with effect of thermal load to the mechanical forging press. Main topic is assessment of displacement on each part of mechanical forging press caused by thermal load. Accuracy of forged part and durability of press is highly influenced by this displacement. Correct settings of thermal simulations lead to proper setting of clearances in structure of mechanical forging press, specially clearance between lower and upper die and in guidance of ram. This can be done generally for all size of press.
\end{abstract}

Keywords: thermal simulation; forging press; heat load, FEM simulation.

\section{Introduction}

Incorrect setting of clearance between upper and lower die can during forging lead to not finished forging or to increased loading of forging machine. Mechanical forging press is during hot forging process working with pre-heated die to temperature $300^{\circ} \mathrm{C}$. This heat (thermal load) is then transmitted to other parts of forging machine. It means to the frame, ram, crankshaft and to the connecting rod. This heat is causing dilatation. Main aim of research is proper description of heating process by using modern numerical methods of modelling and elimination of its influence.

Heat sources occurring on forming machines can be divided into 3 groups:

- Heat from forming technology (hot preform, preheated die) - the subject of this article

- Heat generated in the forming machine (friction between moving members - guiding the moving parts, expansion of the working fluid, friction from clutches and brakes, etc.)

- Heat that is transferred from the surroundings

The working area of the forging presses is mostly influenced by the preheated die. This area has the greatest impact on the accuracy of products. Each size of forging presses is specific, and therefore thermal analysis must be carried out separately for each of them. This article is focused on a mechanical forging press with nominal force 25 MN. [1, 2, 3, 4]

Heat affected area, see Fig 1:

- part of frame

- $\quad$ ram

- guides

- press table 


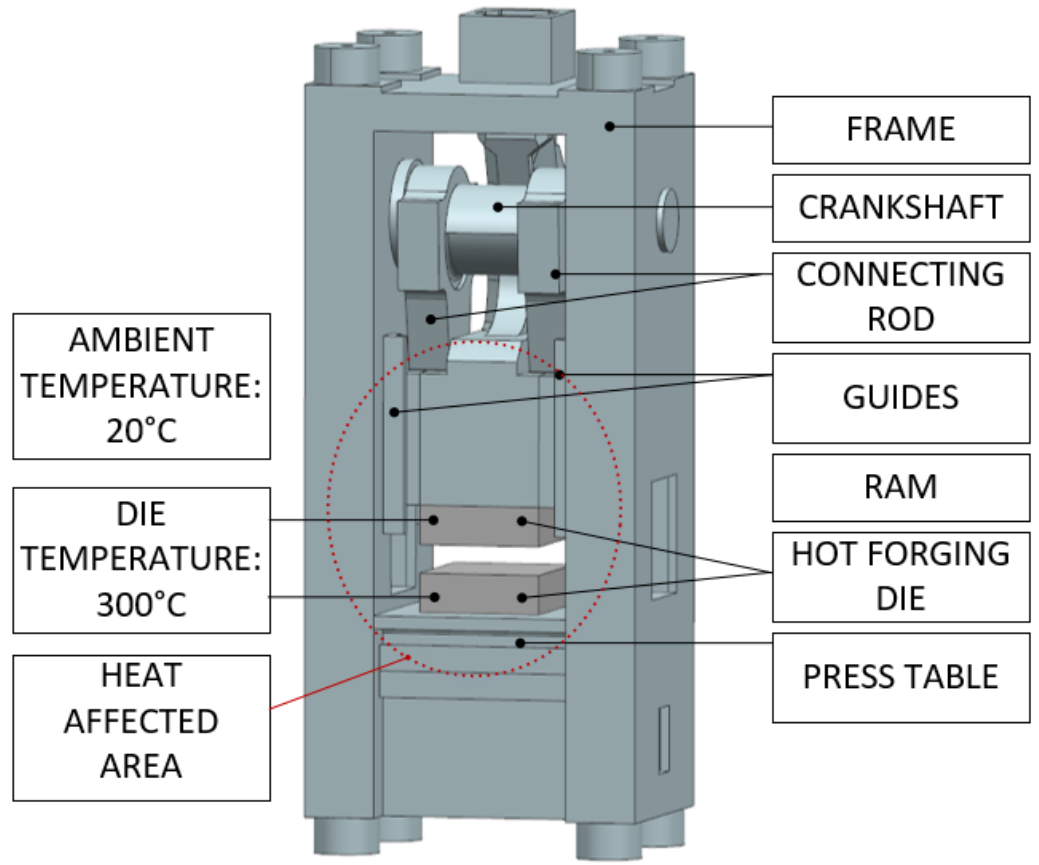

Fig. 1 Description of mechanical forging press and boundary condition of thermal calculation

\section{Boundary conditions of thermal analysis}

When the boundary conditions were determined, efforts were made to capture the least favourable conditions of the real state. The correct determination of boundary conditions is a necessary prerequisite for obtaining relevant results. Boundary conditions must be specified for each machine separately with regard to the operating technologies.

Temperatures of both parts of the die were set to $300{ }^{\circ} \mathrm{C}$, which corresponds to normal preheating. This temperature is kept constant throughout the calculation time. This boundary condition is based on previous research. There was determined, that thermal load caused by forged part is not increasing temperature of preheated die.

Ambient temperature of the press was set to $20{ }^{\circ} \mathrm{C}$. Radiation and convection to environment was during simulation considered. Each part of the press was connected by thermal contacts $[1,2,5,7,8,9]$

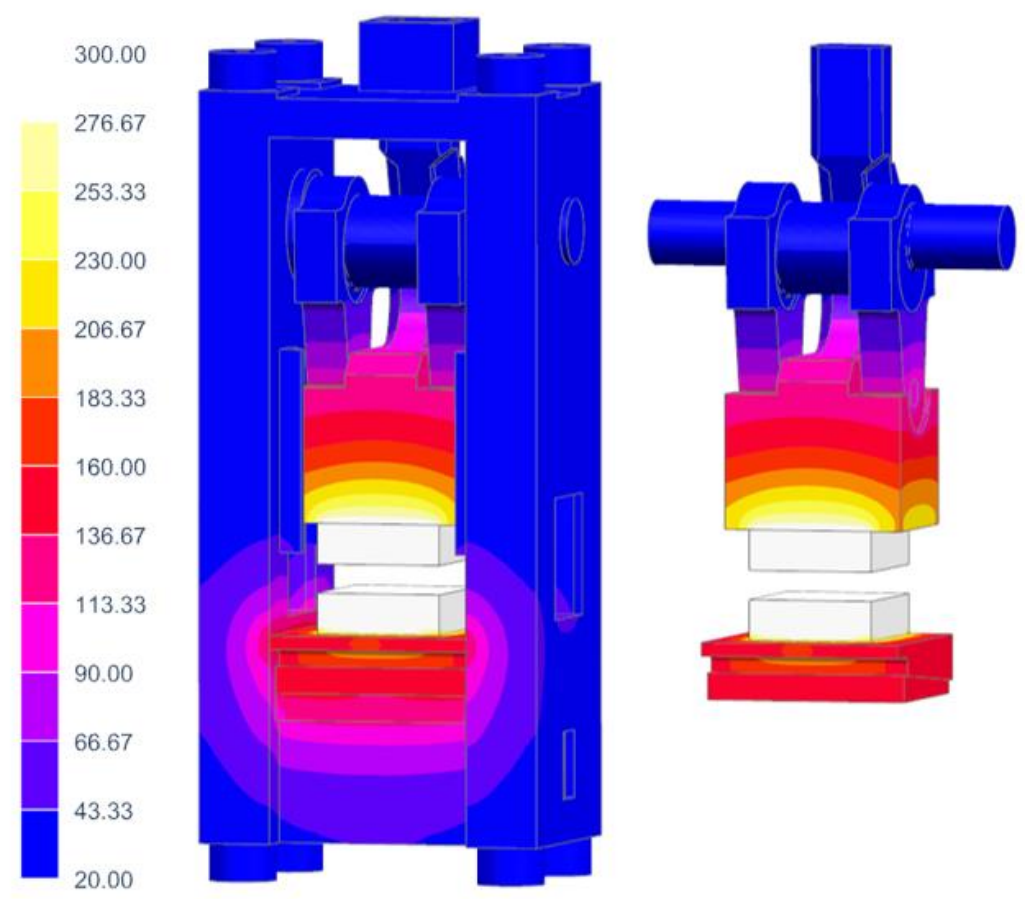

Fig. 2 Temperature load of mechanical forging press $\left[{ }^{\circ} \mathrm{C}\right]$ 


\section{The results of thermal analysis}

The results of the calculation represent the thermal steady state of the structure (see Fig 2), for boundary condition defined in previous text.

The calculation shows that in this case cannot be ignored influence of heat load on the machine. Especially, thermal influence of ram and press frame near the press table is significant.

The maximum temperature on frame, near the press table is $121^{\circ} \mathrm{C}$. The maximum temperature reached inside the ram guides is $116^{\circ} \mathrm{C}$. We can say that the temperature will have a significant influence on defining the clearance between hot forging dies and between ram and guides.

\section{Boundary conditions for structural analysis}

Results from thermal analysis is used as input for following structural analysis. All considered parts of the press (crankshaft, ram, connecting rods, ram, press table) were connected using contacts. Clearance of the guidance was set to $0.1 \mathrm{~mm}$, clearance in the bearings to $0.2 \mathrm{~mm}$. [1,6]

\section{The results of structural analysis}

Another necessary step is the structural calculation for obtaining the results of displacement of the structure. Especially is mentioned comparison between frame elongation (see Fig $3-\Delta \mathrm{L}-$ FRAME) and whole inner system. (see Fig $3-\Delta \mathrm{L}$ - ram, connecting rod crankshaft). This has major impact on clearance between dies.

Following results shows structural loading caused by thermal load from thermal simulation. Displacement results show elongation of frame in area between table and bearing of crankshaft. Value of this elongation is $2.47 \mathrm{~mm}$. Elongation of whole inner system is $4.97 \mathrm{~mm}$. It shows that not considering of thermal influence can lead to machine overloading. It means in this case necessity of elongation $2.5 \mathrm{~mm}$ elimination.

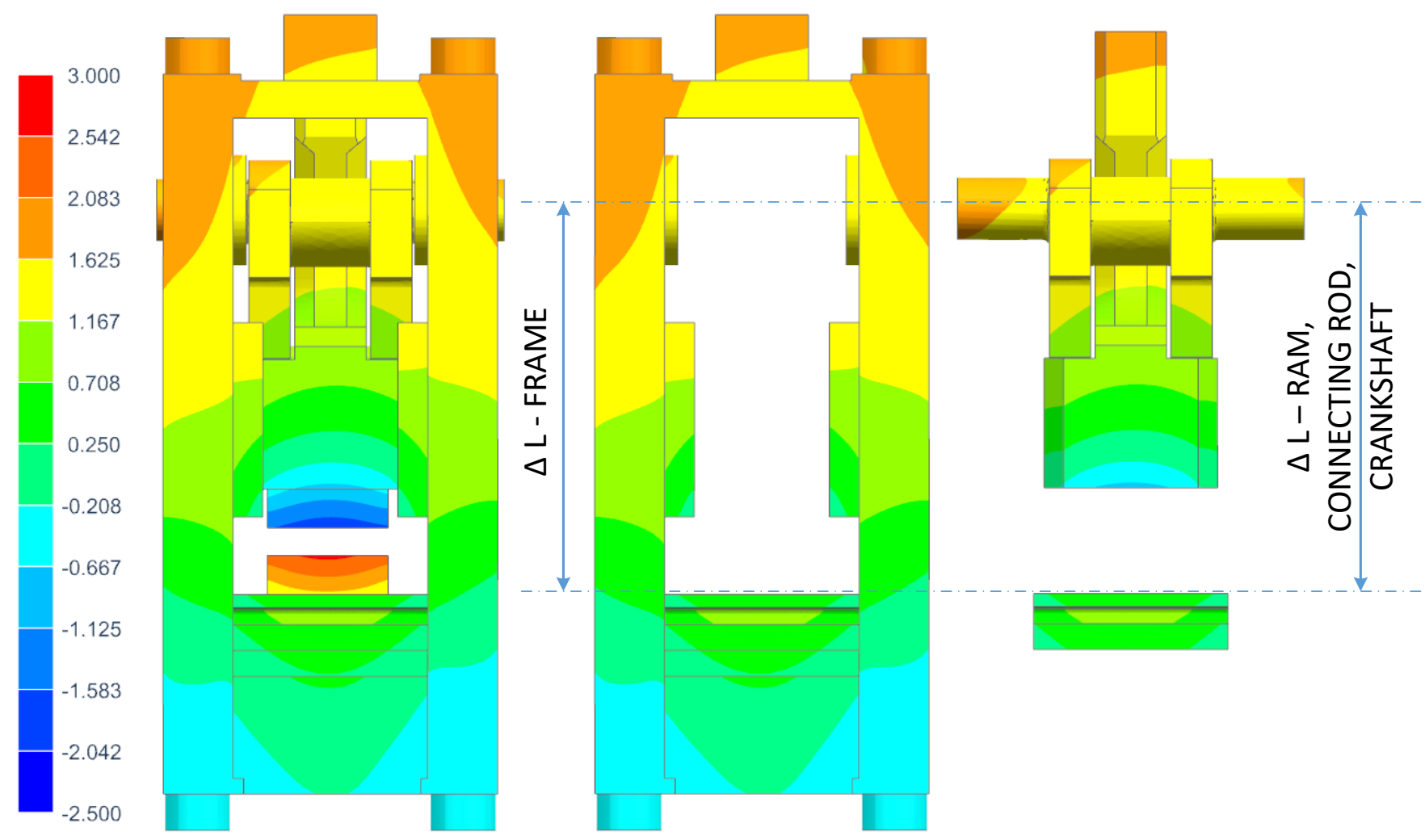

Fig. 3 Displacement of forging press in vertically direction [mm]

Figure 4 shows results of horizontal displacement. Elongation of frame (see Fig $4-\Delta \mathrm{L}-$ FRAME) and ram (see Fig $4-\Delta \mathrm{L}-\mathrm{ram}$ ) has significant influence on clearances setting in ram guides. From results is obvious that elongation of frame in area of guides is $0.92 \mathrm{~mm}$ and ram elongation is $1.2 \mathrm{~mm}$. According these results is necessary to set minimal clearance $0.29 \mathrm{~mm}$ for elimination of thermal expansion. 

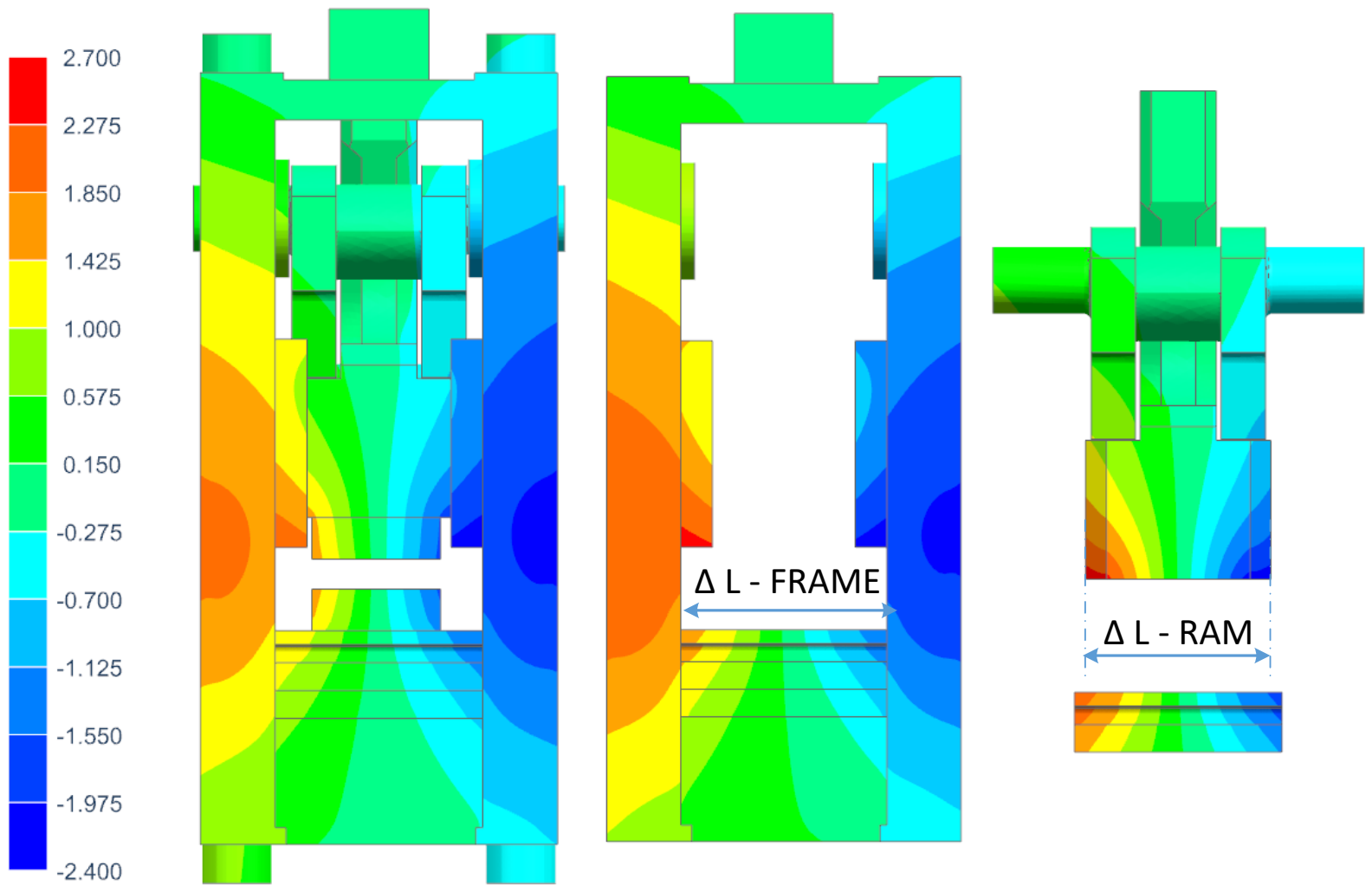

Fig. 4 Displacement of forging press in horizontally direction [mm]

Figure 5 (left) shows stress on ram caused by thermal load. It possible to notice, that clearance in simulation was small and contact between ram and guides occurred. In Figure 5 are also visible areas with higher stress in corners of ram. This are contact locations caused by thermal loading. This situation in praxis means stopping of press. Figure 5 (right) shows stress on ram with changed clearance which allows movement of ram.

Correct settings of clearances have significant influence on forgings quality. When clearances are too big, tilting of ram can occur and this can lead to non-uniform forging. On the other hand, small clearances can lead to press overloading.
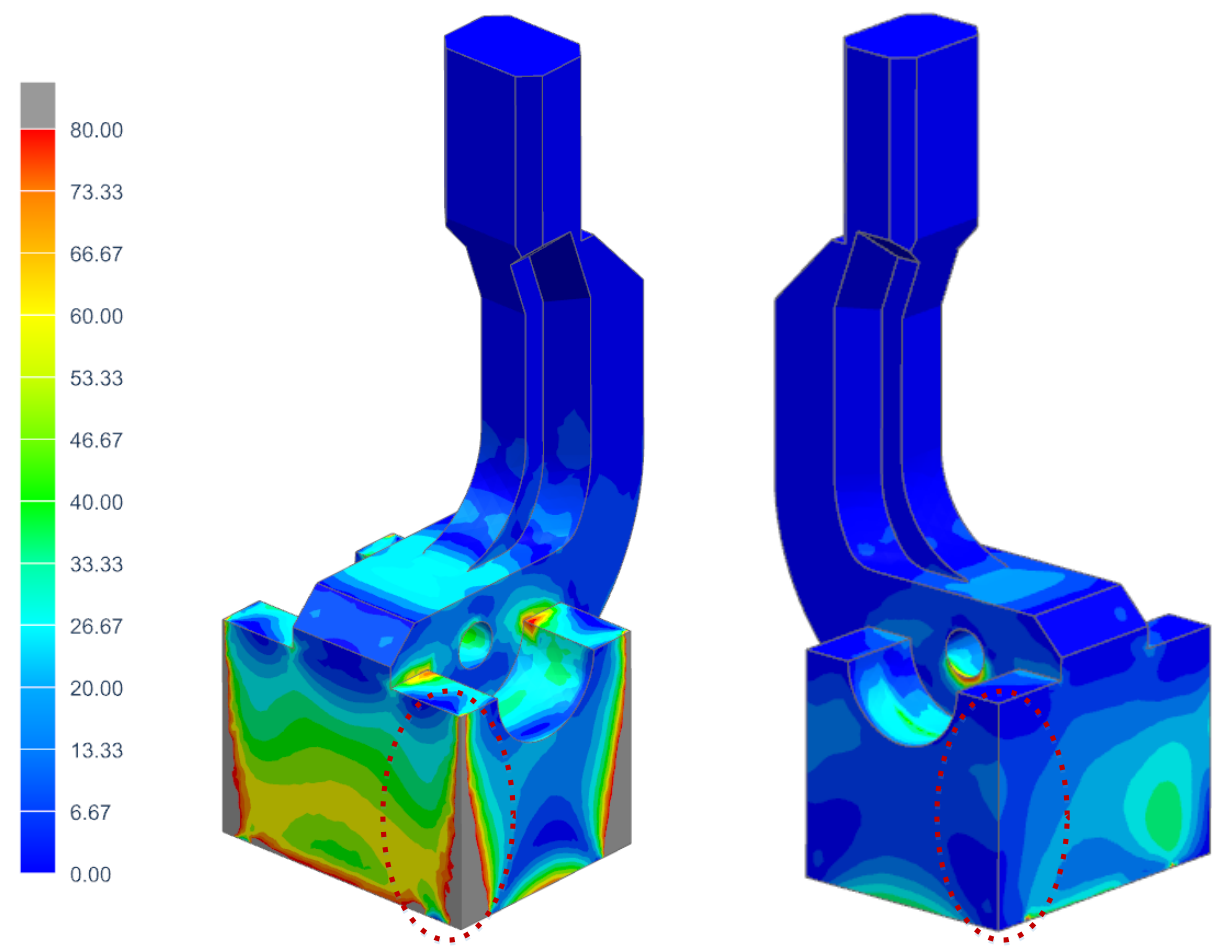

Fig. 5 Stress of ram caused by thermal load with small clearance (left) and sufficient clearance (right) [MPa] 


\section{Conclusion}

By this analysis and research of mechanical forging press is confirmed that influence of thermal load is significant. It is especially visible during clearances investigation. Main influence is on forgings accuracy and press loading.

This research will continue and focused will be on improvement of boundary conditions during virtual simulations. Main aim is including thermal loading directly in structural simulation without additional thermal analysis. Next step is including of die preheating in simulation process.

Next research will be focused also on proper settings of clearance in ram guides with respect to thermal load and also on considering of different types of guides and their influence on accuracy.

Because of energy demands is also important to think about possibilities of energy loos reductions. This loses are caused by heat transfer to surrounding environment.

\section{Acknowledgments}

The article has been prepared under project LO1502 'Development of the Regional Technological Institute under the auspices of the National Sustainability Programme I of the Ministry of Education of the Czech Republic aimed to support research, experimental development and innovation.

\section{References}

[1] Chval, Z. (2013). Effect of Heat Load to the Forming Machines, MM (Modern Machinery) Science Journal, October 2013, ISSN 1805-0476, pp. 418-422

[2] Chval, Z. (2013) Effect of Heat Load on a Forging Press, Annals of DAAAM for 2013 \& Proceedings of the 24st International DAAAM Symposium, Zadar; Croatia; 23 October 2013 through 26 October 2013, ISSN 1877-7058, ISBN 978-3-901509-73-5, Katalinic, B. (Ed.), pp. 0209-0210, Published by DAAAM International Vienna, Vienna

[3] M. Cechura, J. Housa, Energy Analysis of Forming Machines and Further Proposals for Decreasing of Energy Consumption, research report, V-11-037, VSCVTT, Prague, 2011

[4] F. Tikal, M. Duchek, FEM Analyses of the radiation in heating forging furnace, Annals of DAAAM for 2011 \& Proceedings of the $22^{\text {nd }}$ International DAAAM Symposium, ISSN 1726-9679, ISBN 978-3-901509-83-4, Vienna, Austria, EU, 2011

[5] Z. Chval, J. Stanek, Temperature Effect of Molded Piece to Forming Machine, ISBN 978-80-227-3135-5, Bratislava, 2009

[6] M. Cechura, Z. Chval, Convectional Versus Multiple Operating Press, Kovarenstvi, May 2013/17, 67-70, ISSN 1213-9289, Brno, 2013

[7] Selimaj, R. A.; Osmanaj, S. \& Sahiti, N. (2010). Modeling of Temperature and Non-Stationary Heat Flux Through a Flat Wall, Annals of DAAAM for 2010 \& Proceedings of the 21st International DAAAM Symposium, 20-23rd October 2010, Zadar, Croatia, ISSN 1726-9679, ISBN 978-3-901509-73-5, Katalinic, B. (Ed.), pp. 0209-0210, Published by DAAAM International Vienna, Vienna

[8] Cernecky, J. \& Koniar, J. (2010). Research of Local Values of Heat Transfer Coefficients in the Area of Heated Curved Wall, Annals of DAAAM for 2010 \& Proceedings of the 21st International DAAAM Symposium, 20-23rd October 2010, Zadar, Croatia, ISSN 1726-9679, ISBN 978-3-901509-73-5, Katalinic, B. (Ed.), pp. 0315-0316, Published by DAAAM International Vienna, Vienna

[9] Gerlich, V. \& Zalesak, M. (2010). Experimental Validation of Heat Transfer Model, Annals of DAAAM for 2010 \& Proceedings of the 21st International DAAAM Symposium, 20-23rd October 2010, Zadar, Croatia, ISSN 17269679, ISBN 978-3-901509-73-5, Katalinic, B. (Ed.), pp. 0969-0970, Published by DAAAM International Vienna, Vienna

[10] Terziqi, A. K.; Haxhiaj, A. B.; Kamberaj, N. S. \& Bajraktari, B. V. (2010). Thermal Load Impact on Steam Parameters for Cooling the Shaft Furnace, Annals of DAAAM for 2010 \& Proceedings of the 21st International DAAAM Symposium, 20-23rd October 2010, Zadar, Croatia, ISSN 1726-9679, ISBN 978-3-901509-73-5, Katalinic, B. (Ed.), pp. 0173-0174, Published by DAAAM International Vienna, Vienna 